\title{
Artelogie
}

Recherche sur les arts, le patrimoine et la littérature de l'Amérique latine

5 | 2013

Femmes créatrices en Amérique latine : le défi de synthétiser sans singulariser

\section{Editorial: Mulheres criadoras na América Latina: o desafio de sintetizar sem singularizar}

Ana Paula Cavalcanti Simioni, Deborah Dorotinsky e Maira de Luca

\section{OpenEdition}

\section{Journals}

Edição electrónica

URL: https://journals.openedition.org/artelogie/5098

DOI: 10.4000/artelogie.5098

ISSN: $2115-6395$

Editora

Association ESCAL

Refêrencia eletrónica

Ana Paula Cavalcanti Simioni, Deborah Dorotinsky e Maira de Luca, «Editorial: Mulheres criadoras na América Latina: o desafio de sintetizar sem singularizar», Artelogie [Online], 5 | 2013, posto online no dia 16 outubro 2013, consultado o 20 dezembro 2021. URL: http://journals.openedition.org/artelogie/ 5098 ; DOI: https://doi.org/10.4000/artelogie.5098

Este documento foi criado de forma automática no dia 20 dezembro 2021.

Association ESCAL 


\title{
Editorial: Mulheres criadoras na América Latina: o desafio de sintetizar sem singularizar
}

\author{
Ana Paula Cavalcanti Simioni, Deborah Dorotinsky e Maira de Luca
}

1 Entre 1974 e 1979, no bojo do movimento feminista a artista norte-americana Judy Chicago concebeu sua emblemática obra, Dinner Party ,como um banquete simbólico que reuniria 1038 mulheres, de diferentes períodos históricos, estando 39 delas evocadas à mesa, enquanto as demais eram nomeadas nas cerâmicas dispostas na grande instalação, de sorte a celebrar - e ao mesmo tempo promover - uma suposta tradição feminina até então não reconhecida pela historiografia dominante. Nessa grande comunhão, alguns limites etnocêntricos do feminismo anglo-saxão se faziam evidentes, como então notou Estelle Chacon, nenhuma das heroínas do "nuevo mundo" figurava entre as convidadas de honra sentadas à mesa, bem ao contrário, as "hispanas" apareciam, como as negras, nomeadas apenas em alguns ladrilhos, aqueles dispostos ao chão, sinalizando o lugar simbólico que ocupavam nessa nova narrativa proposta pelo feminismo que despontava nos EUA e Inglaterra ${ }^{1}$.

2 As reações à obra, tornada um dos ícones do feminismo da "igualdade", não tardaram. Já em 1977, Griselda Pollock publicava "What's wrong with the Images of Women", denunciando aquilo que denominava como "iconografia vaginal", presente na obra, que tenderia a reduzir as múltiplas identidades femininas a um suposto significante estável, derivado de seus corpos biológicos. Contra uma imagem unívoca, Pollock, que seguramente é hoje o nome mais influente na historiografia da arte feminista, propunha a desconstrução das imagens femininas, a crítica aos discursos estabilizadores, enfim, a todos os tipos de reduções, mesmo aqueles operadas pelo feminismo. A partir da década de 1980 , grosso modo, pode-se dizer que o feminismo da "igualdade" cedeu lugar ao da diferença. Pelo campo da crítica literária pós-colonial, é importante notar a contribuição de Gayatri Chakavorty Spivak em "Imperialism and Sexual Difference" (1986), ao apontar a necessidade de se passar de um feminismo meramente "oposicional" a um feminismo "crítico", capaz de examinar continuamente 
a forma com que o próprio feminismo se imbrica em instituições e ideologias. Nesse sentido, autoras como Chéla Sandoval (1995), tiveram um papel importante ao problematizarem que feminismo anglo-saxão dos anos 1960/70, pressupunha um sujeito feminista único, estável, hegemônico, o qual não traduzia as expectativas, desejos e realidades vivenciadas pelas "outras do feminismo". Assim, as questões "femininas" passavam a ser vistas como atravessadas por fortes de classe social e etnicidade.

3 Pode-se dizer que no campo artístico tal debate fomentou análises que passaram a atentar para a importância das imagens de mulheres propagadas pelas obras de arte, pela mídia, pela imprensa e pelo cinema, como espaços fundamentais de promoção e cristalização de discursos sociais normativos; os quais passam a ser tomados como "tecnologias de gênero" (De Lauretis, 1987). Desde então, mais do que promover imagens positivas sobre a feminilidade, a historiografía da arte feminista, passou a deter-se sobre a crítica de tais representações (Arruda, 2013).

4 No entanto, quando pensamos o campo dos estudos de gênero e arte na América Latina, deparamo-nos com uma situação complexa, pois essa historia do pensamento feminista não ocorre da maneira com que é narrada acima; muitas vezes os textos do feminismo da "igualdade" e da "diferença" chegam as mãos dos leitores em um mesmo intervalo temporal. Além disso, as pesquisas levadas a cabo nutrem-se dos paradigmas desenvolvidos pelas teorias anglo-saxãs, as quais tem como marco fundador o célebre ensaio de Linda Nochlin (1971). Em "Why have there been no great women artists?" a autora argumentou que o pouco reconhecimento das mulheres na história da arte resultava de fatores sociais e institucionais, em especial o acesso desigual às condições de formação artística, estabelecendo assim as balizas sobre as quais se assentariam uma historiografia da arte feminista. No entanto, é preciso reconhecer que as múltiplas realidades contidas no termo "America Latina" são por demais diversas daquelas que ensejaram a emergência de tais teorias feministas, de sorte que necessariamente elas devem ser revisitadas, adaptadas e mesmo reelaboradas quando contrastadas aos diferentes contextos que lhes são apresentados². É ainda preciso lembrar que a recepção de tais postulados não ocorreu de maneira simultânea ou equânime nos países da América Latina. Se no México, já desde inícios da década de 1970 tais textos circulavam e impactavam desde as discussões universitárias, chegando as instituições artísticas, como bem demonstra o artigo de Andrea Giunta aqui publicado, em outros casos, como o do próprio Brasil cuja produção artística feminina e feminista é considerável, ainda hoje o célebre texto não foi sequer traduzido para o português, evidenciando uma circulação restrita. Entre esses extremos, pode-se citar o caso da Argentina, cuja capital, Buenos Aires, é palco de várias experimentações feministas durante os anos 70, como bem analisa Maria Laura Rosa, em "El despertar de la conciencia. Impacto de las teorías feministas sobre las artistas de Buenos Aires durante las décadas del ' 70 y ' 80 ”, produções essas contestatárias e realizadas desde às margens do sistema artístico. Como afirma Luana Saturnino Tvardovskas, em "Tramas feministas na arte contemporânea brasileira e argentina", o fato das produções feministas no Brasil e na Argentina se organizarem de modo distinto dos países anglo-saxões, de maneira menos institucionalizada, menos identitária, não se traduzindo em grandes mostras coletivas ou numa revisão mais contundente do cânone, não retira a força das poéticas feministas contidas em muitas das obras aí produzidas. Tais considerações são relevantes para que se entenda a dificuldade em se construir um arcabouço teórico e metodológico único para compreender produções e 
situações históricas muito diversas entre si. o que se traduz também em impasses e limites curatoriais ainda muito presentes, que se evidenciam nas tentativas de se "incluir" as obras das artistas feministas latino-americanas nas grandes narrativas feministas contemporâneas, as quais tendem a repor hierarquias e retraçar invisibilidades, como bem analisa Erin L. McCutcheon em "Feminism Unfolding: Negotiating In/Visibility of Mexican Feminist Aesthetic Practices within Contemporary Exhibitions".

5 Assim, o presente número da revista Artelogie pretende contribuir para o debate sobre arte e gênero ao abranger um panorama amplo e variado de investigações sobre as mulheres artistas na América Latina, desde o século XIX até as expressões contemporâneas. Não se trata de buscar uma teoria monolítica, ou um mapeamento completo e exaustivo sobre a produção das mulheres artistas em toda a América Latina. Antes, apresentamos ao leitor uma seleção de textos que possuem densidade analítica e verticalidade, mas que cobrem experiências, produções, poéticas realizadas em diversos países num período temporal relativamente largo. Procuramos priorizar aquelas modalidades artísticas que contam com menos publicações (como as artes plásticas, música e design), o que significou uma opção por não abordar as práticas literárias, que contam com uma larga tradição.

6 Em um primeiro bloco estão reunidos ensaios que analisam de que modo as dimensões do gênero perpassam os processos de constituição dos discursos identitários que eclodem ao longo do século XIX em diversos países na América Latina, no bojo de suas lutas por autonomização política. Tais discursos se materializam nas - e por meio das formas artísticas. Ao lado dos romances de fundação (Doris Sommer, 2010), as pinturas constituíam verdadeiros discursos visuais de caráter pedagógico, nos quais por meio de articulações complexas (e tensas), dicotomias vistas então como aparentemente inconciliáveis como entre civilização $x$ barbárie, dominadores brancos $x$ dominados (indígenas/ negros), ativos $x$ passivos, homens $x$ mulheres, podiam ser transcendidas, apaziguadas, ou domesticadas. Nesse processo civilizatório conflituoso, que envolve o dilema da mestiçagem, o corpo feminino ocupa um espaço político, visual e simbólico central, seja no Chile, como demonstra o artigo de Josefina de La Maza sobre as pinturas de Monvoisin, particularmente Elisa Bravo Jaramillo de Bañados, mujer del cacique, seja na jovem república brasileira, como bem analisam Tatiana Lotierzo e Lilia Katri M. Schwarcz, detendo-se na célebre tela Redenção de Cã, pintada por Modesto Broccos.

7 Um outro conjunto de artigos aborda por meio de práticas artísticas distintas como a música, a gravura, a pintura e a escultura, o ingresso das mulheres artistas naquilo que poderíamos denominar como "modernidades periféricas" (Sarlo, 1999). A inserção feminina nos meios artísticos ensejou-se ao longo do século XIX em diversos países latino-americanos, em especial, naqueles que passaram por processos de institucionalização das rotinas artísticas com base em modelos ultramarinos, que culminaram na fundação das Academias de arte, tais como México, Brasil, Argentina e Chile. De um modo geral, seguia-se o modelo da Academia Francesa pós-revolucionária que não previa mulheres como discípulas, mas as aceitava como expositoras nos Salões (Simioni, 2008). Isso significava que as mulheres não possuíam o acesso pleno à formação artística, tal como seus colegas homens, no entanto, certas habilidades eram 
não apenas toleradas, mas fomentadas na medida em que eram constitutivas dos ideais de feminilidade burguês que se disseminavam em tais nações.

Conforme demonstra Georgina Gluzaman em "El trabajo recompensado: mujeres, artes y movimientos femeninos en la Buenos Aires de entresiglos", na Argentina configurava-se uma situação ambígua, permeada por tensões que advinham, por um lado, das expectativas sociais normativas sobre a feminilidade almejada, e, de outro,das condições concretas de profissionalização que desfrutavam. Em "Del caballete al telar. La Academia Nacional de Bellas Artes, las escuelas profesionales y los debates en torno de la formación artística femenina en la Argentina de la primera mitad del siglo XX", Julia Ariza adensa ese panorama ao centrar-se nas condições de formação artística a que as mulheres tinham acesso na Argentina, em pleno proceso de modernização. Gloria Cortez aborda a mesma problemática a partir do caso das artistas chilenas em "Estéticas da resistencia: las artistas chilenas y la vanguardia femenina (1900-1936)", discutindo os óbices à formação enfrentado pelas artistas, bem como as modalidades estéticas de "transgressão" ao discurso patriarcal vigente que elas lograram realizar.Em "Género y cultura visual. Adrienne Macaire-Bacle em La historia del arte argentino", Lia Munilla, Sandra Szir e Georgina Gluzman recuperam a atuação pioneira da gravadora, no começo do século XIX em Buenos Aires, por meio de uma pesquisa original em fontes de época, as autoras discutem a produção negligenciada dessa artista numa modalidade então considerada "menor" e essencialmente "masculina". Também centralizando suas análises nas inter-relações entre gênero e modalidades artísticas, Dalila Vasconcellos em "Du salon à la scène: l'ascension des femmes et du piano au brésil du vingtième siècle ",interpreta a transformação no campo musical brasileiro na Belle époque (c.1889-1930), quando emergem 3 pianistas notáveis (Antonieta Rudge, Magda Tagliaferro e Guiomar Novaes).A autora mostra que paulatinamente a condição de concertista de piano se tornou uma prerrogativa feminina, assinalando que as produções e trajetórias de tais musicistas foram capazes de configurar uma superação das tradicionais assimetrias de gênero, de sorte a inventar uma nova posição para elas no campo musical brasileiro, um lugar socialmente legítimo e reconhecido.

Retomamos aqui o termo "modernidades periféricas" pois nas regiões hispanófonas e lusófanas, os artistas das vanguardas modernistas adotaram e adaptaram algumas das formas derivadas dos repertórios denominados como "étnicos" e/ou "populares", desenvolvendo assim um modernismo híbrido, ou "antropofágico", como também foi denominado ${ }^{3}$.Nesse sentido, alguns artigos são muito reveladores das inserções femininas nos campos dominados, até então, por homens: a arquitetura e o desenho industrial entre os anos 1930 e 1950 no México e no Brasil. Zeuler R. M. De Lima, em "Lina Bo Bardi et l' architecture brésilienne de l' aprés guerre" mostra o desenvolvimento da carreira e da obra arquitetônica de Lina Bo Bardi, arquiteta italiana radicada em São Paulo no final da segunda guerra mundial, a qual realizou obras importantes para o modernismo brasileiro, como o emblemático edificio do MASP (Museu de Arte de São Paulo), mas é pouco reconhecida internacionalmente, ainda que sua notoriedade venha crescendo nos últimos anos ${ }^{4}$.De seu lado, Ana Elena Mallet recupera a trajetória de Clara Porset, uma designer industrial de origen cubana, radicada no México, e mostra como seus vínculos estratégicos com os arquitetos reconhecidos lhe permitiram destacar, por meio de projetos de design de interiores e mobiliários, sua visão acerca da recuperação e amoldamento das formas derivadas do mobiliário popular mexicano. É interesante notar que também Lina Bardi teve uma contribuição teórica fundamental para a valorização do artesanato brasileiro ${ }^{5} .0$ 
problema da articulação entre os ímpetos internacionalistas do modernismo e as injunções locais/nacionais/populares experimentadas e mobilizadas pelas artistas da America Latina é também abordado por Michele Greet, que propõe uma análise comparativa de exposições realizadas por 4 artistas latino-americanas em Paris durante os anos 1920: as brasileiras Tarsila do Amaral e Anita Malfatti, a mexicana Lola Velasquez Cueto e a cubana Amélia Pelaez. A autora demonstra como cada uma delas estabeleceu estratégias distintas para se fazerem notar nos meios parisienses, o que envolveu escolhas acerca dos asuntos a serem representados, bem como da materilialidade de suas obras, evidenciando o quanto tais decisões envolviam negociações complexas sobre as implicações de gênero de cada estilo adotado. Como os artigos permitem entender, a dimensão do gênero discrimina não apenas autores, modalidades, mas também envolve a própria materialidade das práticas artísticas, bem como os graus de legitimidade com que são classificadas nos campos artísticos em que se inscrevem.

10 Finalmente, há um significativo número de artigos que aproximam os trabalhos das mulheres artistas na arte contemporânea, revelando uma variedade de temáticas que preocuparam e ainda dizem respeito a elas: o corpo, a sexualidade, a história das mulheres e as práticas coloniais, a violência de gênero e a maternidade ${ }^{6}$. Analisando o caso do México, que se destaca como um importante centro de produção e reflexão sobre práticas feministas na América Latina durante os anos de 1970, temos os textos "Cosas de mujeres? Feminst networks of collaboration in 1970's Mexico", de Gabriela Aceves, e "FeministDisruption in MexicanArt, 1975-1987", de Andrea Giunta. $O$ artigo de Giunta propõe uma leitura das intervenções realizadas por algumas artistas - Paula Weiss, Mónica Mayer, Magali Lara e a jornalista e ativista feminista Ana Victoria Jiménez - as quais tornaram possível um cenário feminista nos meios artísticos mexicanos: introduziram corporalidades desobedientes e insubordinadas, que freqüentemente foram invisibilizadas pela própria historiografia da arte feminista do país. O texto contribui, assim, para uma leitura que libera o potencial de tais obras pouco convencionais, intervindo em um corpo de imagens imobilizadas por rígidas classificações dos discursos da história da arte.

11 O potencial político e esteticamente transgressor de artistas mulheres é também abordado por uma gama de artigos que revisitam produções realizadas durante os contextos autoritários que grassaram diversos países durante as décadas de $1960 \mathrm{e}$ 1980. As obras como espaços de resistência política e como oposição ao discurso sobre a "natural" domesticidade feminina são interpretadas por Giulia Lamoni em "(Domestic) Spaces of Resistance: Three Artworks by Anna Maria Maiolino, Letícia Parente and Anna Bella Geiger", centrado no caso brasileiro; e também presentes no artigo de Gina McDaniel Tarver, dedicado à produção da escultora colombiana Feliza Bursztyn. A mesma problemática reaparece no artigo de Maria Laura Rosa, que se detém nas obras de María Luisa Bemberg e Monique Altschul, exibindo o grau de consciência política e artística feminista presente em certos circuitos artísticos portenhos em plena ditadura. O artigo de Luana Saturnino aborda a produção de duas artistas, uma argentina e uma brasileira, atuantes no período de passagem a democracia desses dois países (anos 1980 e 1990), as quais, no entanto, são herdeiras de uma poética feminista que eclode e se desenvolve nos decênios anteriores, marcados por feroz autoritarismo. É interessante notar que tais poéticas feministas consistem em "manobras radicais" que buscam contestar os discursos ideológicos vigentes por meio da própria materialidade das obras. Recuperando modalidades comoa costura, a decoração, as obras têxteis, os 
bordados, as aquarelas, tidas tradicionalmente como artesanais e/ou domésticas, e portanto esteticamente inferiores, tais artistas operam deslocamentos de sentidos, ao dotarem-nas de novos sentidos; e assim, desnudam o quanto as assimetrias e desigualdades sociais se inscrevem nos próprios mundos das artes. Subverter, deslocar e desconstruir as imagens de feminilidade passa, desse modo, por transformar as próprias modalidades, práticas e hierarquias artísticas em vigor.

Esse notável conjunto de artigos traça um panorama bastante complexo e contundente sobre a contribuição das artistas mulheres para uma crítica política. Como afirma Nelly Richard, a condição de duplamente dominadas, permitiu às artistas transitarem da "marginalidade como externalidade do poder à margem como questionamento do simbolismo do poder" (Richard, 2011: pg. 40).Mas é preciso notar que, ainda que as obras sejam contundentes, isso não significa que as artistas se identifiquem como "feministas", muitas delas se recusavam, e ainda hoje se recusam, a se verem catalogadas como feministas. Com isso, é preciso destacar a diferença reconhecida desde as práticas artísticas e políticas entre um desejo de militância "geral" e uma militância feminista tout court. Muitas das obras e artistas aqui analisadas possuem obras que assinalam poéticas feministas, sem que suas autoras se vejam atreladas a algum tipo de militância externa ao próprio campo artístico.

13 Nota-se nos textos que se acercam das produções contemporâneas, uma transformação nos meios usados pelas artistas: a fotografia, o vídeo, a instalação e a performance, ou ainda os meios mistos (mixed media) passam a predominar. No caso da artista portoriquenha Elsa María Meléndez, abordado por Raquel Arzola, a manipulação de técnicas mistas como a serigrafia, o entalho em bordado e a montagem em caixas, servem como elementos para uma propor uma sintaxe própria sobre os cenários sociais de circulação do corpo feminino. Também podemos constatar o uso da apropriação e re-significação do imaginário tradicional em uma artista notável, como é a brasileira Adriana Varejão, cuja obra é interpretada por Alice Heeren, evidenciando os cruzamentos entre raça/ gênero e clivagens sociais. Esse tipo de interpretação encontra-se também no artigo de Jamie Ratliff sobre a obra fotográfica de Daniela Rosell, "Ricas y famosas", em que se coloca em questão o tema do espaço doméstico, abordado em outros artigos anteriormente mencionados. Ratliff parte de uma leitura do espaço do "lar" como pedra de toque da nação mexicana, um espaço que tradicionalmente definiu o que significa ser mulher. No texto, o lar aparece como um espaço de representação no qual o poder e a autoridade do Estado invadem as vidas dos cidadãos e permitem a reprodução do poder, por meio da perpetuação dos papéis tradicionais de gênero.

Por fim, gostaríamos de assinalar que o dossiê comporta ainda uma sessão intitulada "Reprises" em que procuramos republicar textos clássicos sobre arte e gênero na América Latina, mas se encontram pouco acessíveis para o público em geral. 0 texto de Laura Malosetti Costa "El rapto de las cautivas blancas: un aspecto erótico dela barbarie en la plástica Rioplatense del siglo XIX" é um dos exemplos pioneiros de interpretação do mito branco da conquista por meio da perspectiva do gênero, do modo com que este aparece na literatura e nas artes plásticas. Com muita criatividade e profundidade, Malosetti entrecruza nesse artigo clásico de sua produção, as fontes literárias e as visuais sobre a subtração das mulheres brancas pelos índios (tanto as cenas de rapto quanto de cativeiro), com o que assinala o cruzamento entre os problemas de gênero, raça e classe social, de maneira muito pioneira. Por outro lado, o artigo de Angélica Velázquez, "Juliana and Josefa Sanromán: The Representation of Bourgeois Domesticity 
in Mexico, 1850-1860" nos apresena a produção plástica das irmãs Sanromán, ambas alunas do director da cadeira de pintura na Academia de San Carlos mostrando o modo com que as senhoritas decimonónicas mexicanas podiam acessar à formação pictórica, bem como o tipo de temáticas que preferiam, de acordo com a classe social a que pertenciam. Ao lado de tais artigos, propusemos uma entrevista com a historiadora da arte argentina Laura Malosetti Costa, cujas reflexões sobre as relações entre arte, gênero e poder, presentes em suas constantes publicações, palestras etc, podem ser tomadas como estímulos à reflexão e pesquisa em outros contextos socio políticos. Os textos aqui reunidos, tomados desde os espaços geopolíticos de sua produção, nos permitem calibrar os alcances das reações frente às construções canônicas dos gêneros, "as guerras" contra tais cânones, como menciona Gloria Cortes, uma vez que hoje em dia é impossível contornar a produtividade crítica e retórica dos contra-discursos (e contra histórias) que os estereótipos de gênero, raça e clase geraram nos países da América Latina.

\section{BIBLIOGRAFIA}

ARRUDA, Lina Alves (2013). Estratégias desconstrutivas: a crítica feminista da representação". Dissertação de Mestrado em Artes Visuais, Escola de Comunicações e Artes, São Paulo, 2013.

BROUDE, Norma Broudeand and GARRARD, Marry (1982). Feminist Art History: Questioning the Litany.New York, Harper \& Row Publishers.

BARTRA, Eli. (2005) Mujeres en el Arte Popular. De Promesas, traiciones, monstrous y celebridades. México, Universidad Autónoma Metropolitana.

CANCLINI, Nestor G. (1990). Culturashibridas. Estrategias para entrar y salir de lamodernidad, México, Grijalbo.

DE DIEGO, Estrella (2008). "Durante El feminismo de la igualdad: Historiografía, teoría y prácticas artísticas”. Madrid, Exitbook: feminismo y arte de género, n.9.

DE LAURETIS, Teresa. (1987). Technologies of Gender.Essays on Theory, Film and Fiction.Bloominton, Indiana University Press.

DOROTINSKY, Deborah (2008). “Mirar desde los márgenes o los márgenes de la mirada. Fotografía por dos mujeres indígenas de Chiapas”, Debate Feminista, Año 19,Vol. 38, octubre 2008.

EDER, Rita. (1982). "Las mujeres artistas en México”, en Anales del Instituto de Investigaciones Estéticas, México, IIE-UNAM, Vol XIII, núm. 50, tomo 2, pp.251-259.

FERRAZ, Isa Grinspum (org.)(1994). Tempos de grossura. O design no impasse. Série Pontos sobre o Brasil. São Paulo, Instituto Lina Bo e P.M. Bardi.

GIASSON, Patrice (ed.) (2010). Brincando fronteras. Creaciones locales mexicanas y globalización. México, CONACULTA.

GIUNTA, Andrea (2011). “Estrategias de lamodernidad en América Latina”. In: Escribir las Imágenes.Buenos Aires, SigloVeintiuno. 
HOLANDA, Heloisa e HERKENHOFF, Paulo (2006).Manobras radicais. Rio de Janeiro, Centro Cultural Banco do Brasil.

HUYSSEN, Andrea (2010). “Geografias Del Modernismo”, In: Modernismo Después de la Posmodernidad.Buenos Aires, Gedisa Editorial.

JONES, Amelia (2011). “ Les politique ssexuelles de The Dinner Party. Un contexte très critique (1996-2005), IN: DUMONT, Fabienne (ed). La Rébellion du Deuxième Sexe. L'histoire de l'art au crible des théories féministes anglo-américaines (1970-2000). Les Presses du Reél.

MAYAYO, Patricia. (2008). '¿Por qué no ha habido (grandes) artistas feministas en España?. Apuntes sobre una historia en busca de autor' en Xabier Arakistain; Lourdes Méndez:Producción artística y teoríadel arte: nuevos debates I, Vitoria, Centro Cultural MontehermosoKulturunea.

NOCHLIN, Linda (1991).Why there be no great women artists?". In:_Art and Sexual Politics. New York, Macmillan Publishing Co.

POLLOCK, Griselda.(1999) “Tracing figures of presence, naming ciphers of abscence. Feminism, Imperialism, and Post modernity in the Work of SutapaBiswas". In BLOOM, Lisa. (1999) With other eyes. Looking at Race and Gender in Visual Culture.Minneapolis / Londres, University of Minnesota Press.

POLLOCK, Griselda (1977). “What's wrong with Images of Women?”, Screen Education, 1977, no24, 25-33.

RUBINO, Silvana (2009). Lina por escrito: textos escolhidos de Lina Bo Bardi, 1943-1991. São Paulo, Cosac\&Naify.

SANDOVAL, Chéla Sandova (1995).l "Feminist forms of Agency and Oppositional Consciousness: U.S. Third World Femenist Criticism" en KEGAN GARDINER, Judith. (1995) Provoking Agents.Genderand Agency in Theoryand Practice. Urbana and Chicago, Universityof Illinois Press.

SARLO, Beatriz (1999). Una Modernidad Periférica: Buenos Aires 1920-1930. Buenos Aires, Nueva Vision. SCHWARTZ, Jorge (2003). Brasil: 1920-1950. Da Antropofagia à Brasília.São Paulo: Museu de Arte Brasileira/ Cosac \&Naify.

SIMIONI, Ana Paula C. (2008). Profissão artista: pintoras e escultoras acadêmicas brasileiras (1884-1922). São Paulo, EDUSP/FAPESP.

SPIVAK, Gayatri Chakravorty. (1986) “Imperialismand Sexual Difference”.oxford Literary Review 8, pp.517-529.

SOMMER, Doris. (2010)“Um romance irresistible: las ficciones fundacionales de América Latina”. In: BHABHA, Homi (compilador). Nación y Narración. Buenos Aires, SigloVeintiuno Editores.

\section{NOTAS}

1. Sobre a obra ver link: https://www.brooklynmuseum.org/exhibitions/dinner_party/

2. É interessante notar que algumas autoras espanholas estabeleceram críticas muito semelhantes à necessidade de se repensar a hegemonia dos modelos anglo-saxões para explicar a produção artística de seu país; a esse respeito ver DE DIEGO (2008); MAYAYO (2008). Para um aprofundamento sobre esse tema, ler os artigos de Luana Saturnino e Maria Laura Rosa presentes no dossiê. 
3. A bibliografia sobre essa questão é extremamente vasta para ser listada por completo. Destacamos: Canclini (1990), Sarlo (1999), Schwartz (2003); Huyssen (2010), Giunta (2011), entre outros.

4. Rubino, Silvana (2009).

5. A esse respeito ler o texto "Tempo de Grossura", inicialmente publicado em 1980, e organizado por Isa Grispum Ferraz (1994).

6. As editoras estão conscientes que o tema das artistas de origem indígena não foi contemplado conforme seria importante. A esse respeito consultar, entre outros, Bartra (2005); Dorotinsky (2008) y Patrice Giasson (Ed., 2010)

7. HOLANDA, H. e HERKENHOFF (2006).

\section{AUTORES}

\section{ANA PAULA CAVALCANTI SIMION}

IEB/USP

DEBORAH DOROTINSKY

UNAM

MAIRA DE LUCA

CRAL-EHESS 